Proceedings of the Online Conference "Applications of Physics in Mechanical and Material Engineering"

\title{
Analysis of Nusselt Number for Natural Convection in Package of Square Steel Sections
}

\author{
R. WYCZÓŁKOWSKI ${ }^{a, *}$, J. SZMIDLA ${ }^{a}$, \\ M. GAEA ${ }^{a}$ AND V. BAGDASARYAN ${ }^{b}$ \\ ${ }^{a}$ Częstochowa University of Technology, 42-201 Częstochowa, Poland \\ ${ }^{b}$ Warsaw University of Life Sciences - SGGW, 02-787 Warsaw, Poland \\ Doi: $10.12693 /$ APhysPolA.139.548 \\ *e-mail: rafal.wyczolkowski@pcz.pl
}

\begin{abstract}
The paper analyses the Nusselt number for natural convection in the inner area of square 40, 60 and $80 \mathrm{~mm}$ sections in the temperature range $20-700^{\circ} \mathrm{C}$. The obtained values of the $\mathrm{Nu}$ number are in the range 1.5-7.2. For each section the maximum value of the $\mathrm{Nu}$ occurs at a temperature amounting to approximately $60-90^{\circ} \mathrm{C}$. This is the effect of the simultaneous influence of the temperature difference within the section $\Delta t$, the kinematic viscosity and the coefficient of thermal expansion of air. The natural convection depending on the section size increases the heat transfer within gas from 1.5 to 4.3 times upon averaging for the whole temperature range.
\end{abstract}

topics: natural convection, steel section, heat treatment, Nusselt number

\section{Introduction}

In industrial heat treatment of steel products, in many situations there is a need to heat a charge of a porous structure $[1,2]$. One of the examples of such a charge are packages of square steel sections (Fig. 1). The porosity of such packages can even exceed 0.9 .

The heating time of such a charge, which is one of the basic technological parameters, depends on many factors. This time depends, among other things, on the natural convection of gas within individual sections. This is a case of convection in a horizontal enclosure. A full description of this phenomenon requires taking into account the fluid motion within the section while considering

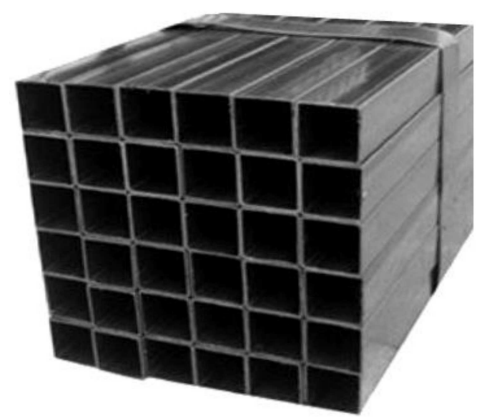

Fig. 1. A package of square steel sections. the influence of all closing surfaces at the same time [3]. Therefore, simplified solutions are being sought. One of the methods applied in this regard consists in expressing the convection phenomenon in a quantitative manner with the use of the Nusselt number $(\mathrm{Nu})$ [4]. The experimental research conducted by the authors has shown that the Nusselt number changes in a very characteristic manner during heating of the sections [5].

The aim of the present work is to determine: (i) the value of the Nusselt number for the analyzed square profiles $(40,60$ and $80 \mathrm{~mm}$ ) in the temperature range $200-700^{\circ} \mathrm{C}$, (ii) the influence of the dimensions of a section, the temperature distribution in a section and the thermo-physical properties of air on the value of the $\mathrm{Nu}$ number.

\section{Analysis and modeling}

Natural convection within the section is always connected with conduction in gas. Both phenomena can be treated jointly as intensified heat conduction expressed quantitatively by equivalent gas thermal conductivity $k_{\text {eg }}[6]$ :

$$
k_{\text {eg }}=k_{\mathrm{g}} \mathrm{Nu} \text {, }
$$
where $k_{g}$ is the thermal conductivity of gas, $\mathrm{Nu}$ the Nusselt number.

The notation of (1) means that the $\mathrm{Nu}$ number is the measure of the intensification of heat transfer caused by the occurrence of natural convection in 




Fig. 2. A package of $60 \mathrm{~mm}$ sections in the chamber of the electric furnace.

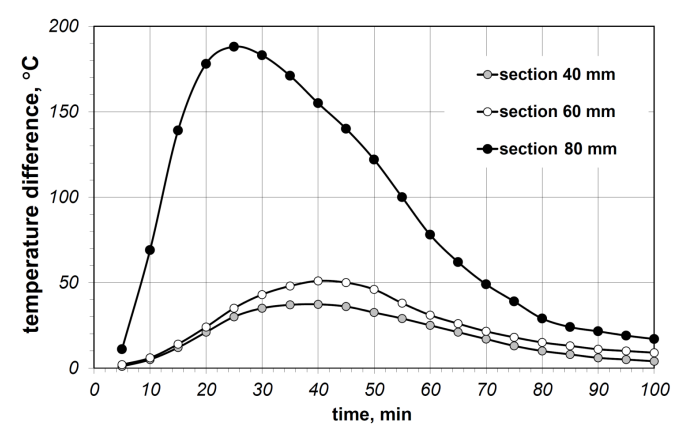

Fig. 3. The values of $\Delta t$ parameter in the function of heating time.

relation to pure conduction. For natural convection of air in horizontal enclosures the following correlations are recommended [6]:

$$
\begin{aligned}
& \text { - for } 10^{4}<\mathrm{Ra}<4 \times 10^{5} \\
& \mathrm{Nu}=0.195 \mathrm{Ra}^{1 / 4} \\
& \text { - for } 4 \times 10^{5}<\mathrm{Ra}<10^{7} \\
& \mathrm{Nu}=0.068 \mathrm{Ra}^{1 / 3} .
\end{aligned}
$$

The Rayleigh Ra number is defined as:

$$
\mathrm{Ra}=\frac{g \beta \Delta t L_{c}^{3}}{\nu^{2}} \mathrm{Pr},
$$

where $g$ is the gravitational acceleration, $\beta$ - the coefficient of volume expansion, $\Delta t$ - the temperature difference between surfaces of the enclosure, $L_{c}$ - the characteristic length of the geometry (for a section this is the distance between the inner surfaces), $\nu$ - the kinematic viscosity of the fluid, $\mathrm{Pr}$ - the Prandtl number, for air regardless of temperature $\operatorname{Pr}=0.71[6]$.

In order to determine the value of the $\mathrm{Nu}$ number for the heated package according to (4), it is necessary to have information about the $\Delta t$ parameter. This knowledge has been obtained thanks to experimental research that consisted in heating packages of square 40, 60 and $80 \mathrm{~mm}$ sections to $700{ }^{\circ} \mathrm{C}$ in a laboratory electric chamber furnace [7]. One of the packages inside the furnace is presented in Fig. 2. During this process the temperature within chosen sections was measured with the

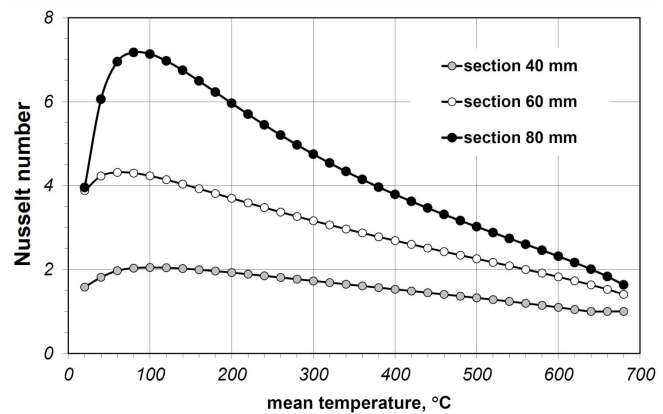

Fig. 4. The results of the Nu number calculation in the temperature function.

TABLE I

Maximum and mean $\Delta t$ values for particular sections.

\begin{tabular}{c|c|c}
\hline \hline Section $[\mathrm{mm}]$ & $\Delta t_{\max }\left[{ }^{\circ} \mathrm{C}\right]$ & $\Delta t_{\text {mean }}\left[{ }^{\circ} \mathrm{C}\right]$ \\
\hline 40 & 38 & 25 \\
60 & 53 & 38 \\
80 & 186 & 137
\end{tabular}

use of sheathed thermocouples. The values of $\Delta t$ have been calculated on the basis of measurement data - the changes of this parameter in the heating time function are presented in Fig. 3. As can be seen, this parameter depends fundamentally on the dimensions of a section, taking the highest values between the 20th and the 50th minute of heating. The maximum and mean values of $\Delta t$ obtained for individual sections have been collated in Table I.

A description of $\Delta t$ changes in the function of mean temperature of a section can be provided in further analysis using

$$
\begin{aligned}
& \Delta t_{40}=3.8 \times 10^{-7} t_{m}^{3}+1.6 \times 10^{-4} t_{m}^{2} \\
& \quad+0.09 t_{m}-1.25 \\
& \Delta t_{60}=3.8 \times 10^{-4} t_{m}^{2}+0.28 t_{m}-0.04 \\
& \Delta t_{80}=8.4 \times 10^{-7} t_{m}^{3}+2.3 \times 10^{-3} t_{m}^{2} \\
& \quad+1.3 t_{m}-15.4
\end{aligned}
$$

Maximum temperature differences for individual sections have been noted at the following $t_{m}$ values: sect. $40 \mathrm{~mm}-460^{\circ} \mathrm{C}$, sect. $60 \mathrm{~mm}-360^{\circ} \mathrm{C}$, sect. $40 \mathrm{~mm}-340^{\circ} \mathrm{C}$.

The changes of kinematic viscosity of air in the $t_{m}$ function have been described by [8]:

$$
\begin{aligned}
\nu & =6.8 \times 10^{-11} t_{m}^{2}+9.5 \times 10^{-8} t_{m} \\
& +1.3 \times 10^{-5} .
\end{aligned}
$$

For the given temperature range, the minimum, mean and maximum values of $v$ equal, respectively, $1.49 \times 10^{-5} \mathrm{~m}^{2} / \mathrm{s}, 5.73 \times 10^{-5} \mathrm{~m}^{2} / \mathrm{s}$ and $1.1 \times 10^{-4} \mathrm{~m}^{2} / \mathrm{s}$.

Based on the relationships (2)-(8), the calculations of the $\mathrm{Nu}$ number have been done. The obtained results in the $t_{m}$ function are presented in Fig. 4. 

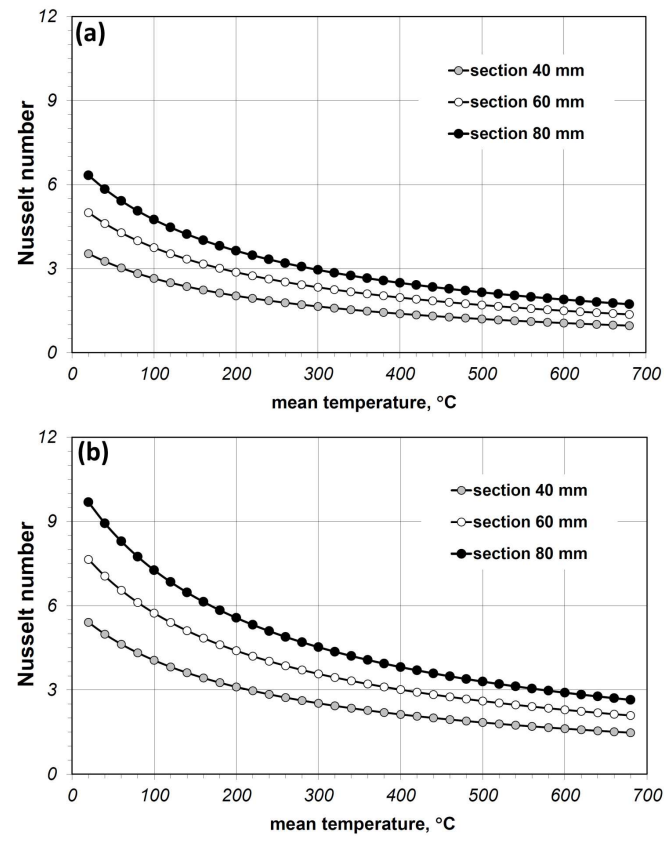

Fig. 5. The values of the Nu number obtained for constant values of the temperature difference: (a) $\Delta t=25^{\circ} \mathrm{C}$, (b) $\Delta t=137^{\circ} \mathrm{C}$.

TABLE II

Maximum and mean $\mathrm{Nu}$ values depending on the section inner size $L_{\text {in }}$.

\begin{tabular}{c|c|c|c}
\hline \hline Section $[\mathrm{mm}]$ & $L_{\text {in }}[\mathrm{mm}]$ & $\mathrm{Nu}_{\max }$ & $\mathrm{Nu}_{\text {mean }}$ \\
\hline 40 & 34 & 2.05 & 1.57 \\
60 & 54 & 4.32 & 2.95 \\
80 & 74 & 7.17 & 4.34
\end{tabular}

As can be seen for each section the changes in the Nu number are of a very similar nature - the maximum value in each case occurs at the temperature of approximately $60-90^{\circ} \mathrm{C}$. Above this temperature a nearly linear decline of the $\mathrm{Nu}$ is observed. Table II collates values of the $\mathrm{Nu}$ number (maximum and mean for the whole temperature range) for individual sections.

The values of $\mathrm{Nu}_{\max }$ and $\mathrm{Nu}_{\text {mean }}$ in the $L_{\text {in }}$ function change linearly which can be noted in the form of

$$
\begin{aligned}
& \mathrm{Nu}_{\text {max }}=12.8 L_{\text {in }}-2.39, \\
& \mathrm{Nu}_{\text {mean }}=6.92 L_{\text {in }}-0.79 .
\end{aligned}
$$

In order to establish which factors determine such characteristic changes in the $\mathrm{Nu}$ number, further calculations have been done. First of all, calculations for constant values of $\Delta t$, equal to $25^{\circ} \mathrm{C}$ and $137^{\circ} \mathrm{C}$ have been done (Fig. 5a and b). In this situation the decline in the $\mathrm{Nu}$ value is observed within the whole temperature range. This result indicates that the initial increase of the $\mathrm{Nu}$ is attributable to the increase in the $\Delta t$ parameter.



Fig. 6. The values of the $\mathrm{Nu}$ number for an $80 \mathrm{~mm}$ section obtained at constant values of the kinematic viscosity.

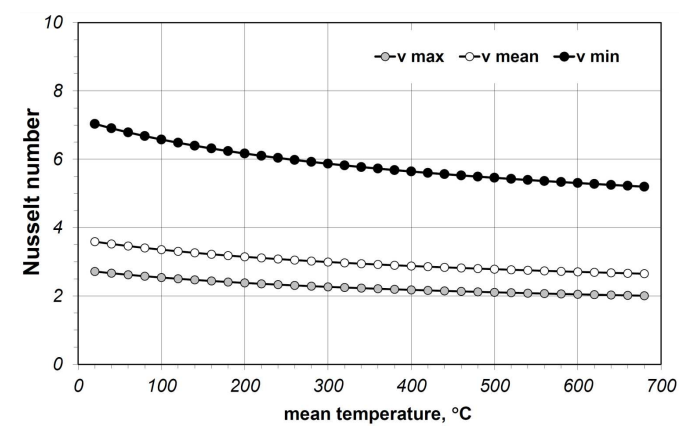

Fig. 7. The values of the Nu number for an $80 \mathrm{~mm}$ section obtained at constant values of the kinematic viscosity and $\Delta t=38^{\circ} \mathrm{C}$.

The following results apply to the $80 \mathrm{~mm}$ section and constant values of $\nu$ : the minimum, mean and maximum ones (Fig. 6). The diagram shows that viscosity changes in the temperature function are responsible for the decline of $\mathrm{Nu}$ which can be observed above $80^{\circ} \mathrm{C}$. The results in Fig. 7, in turn, apply to the calculations for constant $\nu$ and $\Delta t$ values - they show that the decline in the Nu number is also attributable to the coefficient of thermal expansion $\beta$.

\section{Conclusions}

It has been established that the Nusselt number, which expresses the natural convection in the inner area of square steel sections, changes linearly in the function of the inner dimension of the section. This number reaches the maximum value at mean section temperature amounting to approximately $60-90^{\circ} \mathrm{C}$. This result is the effect of the simultaneous influence of the changes in values of the following parameters: the temperature difference within the section $\Delta t$, the kinematic viscosity $\nu$ and the coefficient of thermal expansion $\beta$. At the same time, the initial increase in the $\mathrm{Nu}$ is attributable to the $\Delta t$ parameter. It has been established that the occurrence of natural convection depending on the size of a section increases the heat transfer within gas from 1.5 to 4.3 times upon averaging for the whole temperature range. 


\section{References}

[1] C. Kolmasiak, T. Wyleciał, Metalurgija 7, 368 (2018).

[2] D. Musiał, Arch. Metall. Mater. 1, 63 (2013).

[3] S. Wyczółkowski, "Modelling of Steady Free Convection in Two-Dimensional Enclosed Space", Series Monographs 52, Czestochowa University of Technology, Czestochowa 1998 (in Polish).
[4] A. Bejan, Convection Heat Transfer, 4th Ed., Wiley, 2013.

[5] R. Wyczółkowski, M. Gała, V. Bagdasaryan, App. Sci. 10, 9044 (2020).

[6] Y.A. Cengel, Heat and Mass Transfer A Practical Approach, 3rd Ed. McGrawHill, New York 2007.

[7] R. Wyczółkowski, Civ. Env. Eng. Rep. 14, 119 (2014).

[8] R. Wyczółkowski, Arch. Ther. bf 35, 105 (2015). 